\title{
Genotoxic effect of exposure to metal(loid)s. A molecular epidemiology survey of populations living and working in Panasqueira mine area, Portugal
}

\author{
Patrícia Coelho $^{\mathrm{a}, *}$, Julia García-Lestón ${ }^{\mathrm{b}}$, Solange Costa ${ }^{\mathrm{a}, \mathrm{c}}$, Carla Costa $^{\mathrm{a}}$, Susana Silva a ${ }^{\text {, Valentina Dall'Armi }}{ }^{\mathrm{d}}$, \\ Roberto Zoffoli ${ }^{\mathrm{d}}$, Stefano Bonassi ${ }^{\mathrm{d}}$, João Pereira de Lima ${ }^{\mathrm{e}}$, Jorge Francisco Gaspar ${ }^{\mathrm{e}}$, Eduardo Pásaro ${ }^{\mathrm{b}}$, \\ Blanca Laffon ${ }^{\mathrm{b}}$, João Paulo Teixeira ${ }^{\mathrm{a}, \mathrm{c}}$ \\ a National Institute of Health, Environmental Health Department, Rua Alexandre Herculano n321, 4000-055 Porto, Portugal \\ b Toxicology Unit, Department of Psychobiology, University of A Coruña, Campus Elviña s/n, 15071 A Coruña, Spain \\ ' Institute of Public Health, University of Porto, Rua das Taipas, n135, 4050-600 Porto, Portugal \\ ' Unit of Clinical and Molecular Epidemiology, Istituto di Ricovero e Cura a Carattere Scientifico San Raffaele Pisana, Via di Val Cannuta, 247, 00166 Roma, Italy \\ e Faculty of Medical Sciences UNL, Department of Genetics, Rua da Junqueira 96, 1349-008 Lisbon, Portugal
}

\section{A R T I C L E I N F O}

Article history:

Received 13 April 2013

Accepted 18 August 2013

Available online 13 September 2013

\section{Keywords:}

Environmental contamination

Genetic polymorphisms

Genotoxicity biomarkers

Metal(loid)s

Mining activities

\begin{abstract}
A B S T R A C T
Previous studies investigating the exposure to metal(loid)s of populations living in the Panasqueira mine area of central Portugal found a higher internal dose of elements such as arsenic, chromium, lead, manganese, molybdenum and zinc in exposed individuals. The aims of the present study were to evaluate the extent of genotoxic damage caused by environmental and occupational exposure in individuals previously tested for metal(loid) levels in different biological matrices, and the possible modulating role of genetic polymorphisms involved in metabolism and DNA repair. T-cell receptor mutation assay, comet assay, micronucleus (MN) test and chromosomal aberrations (CA) were performed in a group of 122 subjects working in the Panasqueira mine or living in the same region. The modifying effect of polymorphisms in GSTA2, GSTM1, GSTP1, GSTT1, XRCC1, APEX1, MPG, MUTYH, OGG1, PARP1, PARP4, ERCC1, ERCC4, and ERCC5 genes was investigated. Significant increases in the frequency of all biomarkers investigated were found in exposed groups, however those environmentally exposed were generally higher. Significant influences of polymorphisms were observed for GSTM1 deletion and OGG1 rs1052133 on CA frequencies, APEX1 rs1130409 on DNA damage, ERCC1 rs3212986 on DNA damage and CA frequency, and ERCC4 rs1800067 on MN and CA frequencies. Our results show that the metal(loid) contamination in the Panasqueira mine area induced genotoxic damage both in individuals working in the mine or living in the area. The observed effects are closely associated to the internal exposure dose, and are more evident in susceptible genotypes. The urgent intervention of authorities is required to protect exposed populations.
\end{abstract}

(c) 2013 Elsevier Ltd. All rights reserved.

\section{Introduction}

Mining industry is a major economic resource for many countries, although it is one of the most hazardous activities, both for workers and for the surrounding environment. Panasqueira mine area is one of the most important Portuguese mining sites, and the environmental effect of this activity is a source of great concern. Environmental studies performed in this area identified an anomalous concentration of several metals and metalloids [= metal(loid)s] in stream sediments, superficial and ground waters from local courses, road dust, soils, and plants for human consumption from nearby villages (Ávila et al., 2008; Ferreira da Silva et al., 2013; Grangeia et al., 2011; Salgueiro et al., 2008). Indeed, populations living in the small villages around the mine site are strongly

\footnotetext{
* Corresponding author. Tel.: + 351966441555 (mobile).

E-mail address: pcscoelho@gmail.com (P. Coelho).
}

dependent on agriculture and farming, and moreover the local river flowing nearby - Zêzere river - feeds the Castelo do Bode dam (located $90 \mathrm{Km}$ downstream from the mine), the principal water supply for the Lisbon metropolitan area. Any significant spillages into the river can cause serious environmental contamination and potential health consequences to populations living downstream.

Most metal(loid)s are very toxic to living organisms and when present in excess may become an important threat for the human health. This is also true for even those elements that are considered as essential (Murray et al., 2009). Major health effects include developmental retardation, endocrine disruption, kidney damage, immunological and neurologic effects, and several types of cancer (Mudgal et al., 2010).

A number of studies have been published on the genotoxic effects of metal(loid)s, demonstrating that elements like arsenic (As), cadmium $(\mathrm{Cd})$, chromium $(\mathrm{Cr})$, iron $(\mathrm{Fe})$, mercury $(\mathrm{Hg})$, manganese 
$(\mathrm{Mn})$, nickel $(\mathrm{Ni})$, lead $(\mathrm{Pb})$, and their compounds increase the frequency of micronuclei (MN), chromosomal aberrations (CA), sister chromatid exchanges (SCE), and also chromosomal loss (reviewed in Jadhav et al., 2006). Hartwig (1994) postulated a mechanism of genotoxicity based on the interference of some metal(loid)s with the fidelity of DNA repair. Subsequent studies confirmed that metal(loid)s such as As, Cd, cobalt (Co), and Ni interfere with both base and nucleotide excision repair (BER and NER) pathways (HERAG05, 2007).

Individuals working in the Panasqueira mine and populations living nearby were previously tested for metal(loid) contents in different biological matrices (Coelho et al., in press). The results revealed that the populations are exposed to significantly higher concentrations of $\mathrm{As}, \mathrm{Cr}, \mathrm{Mn}, \mathrm{Mo}, \mathrm{Pb}$, and $\mathrm{Zn}$ when compared to matched controls. The group environmentally exposed showed higher levels of metal(loid)s than the one occupationally exposed, with females presenting significantly higher concentrations of toxic substances than males. Preliminary studies performed in a smaller group of individuals living and working in the area revealed increased levels of MN and T-cell receptor mutations in exposed populations (Coelho et al., 2011, 2012).

The current study was designed to investigate the presence of genotoxic damage associated with both occupational and environmental exposure to metal(loid)s. TCR mutation assay, MN test, CA, and comet assay were analysed as biomarkers of genotoxic effect.

A number of polymorphisms of genes involved in the metabolism (GSTA2, GSTM1, GSTP1, and GSTT1) and in DNA repair (XRCC1, APEX1, MPG, MUTYH, OGG1, PARP1, PARP4, ERCC1, ERCC4, and ERCC5) were selected according to the literature and investigated as possible effect modifiers (Hartwig, 1994; HERAG05, 2007; Mateuca et al., 2008; Skjelbred et al., 2011; Teixeira et al., 2002).

\section{Methods}

\subsection{Study population}

The study population consisted of a total of 122 subjects living in the area of the Panasqueira mine as detailed in Coelho et al. (in press). Forty-one individuals living in villages located in the vicinity of the mine and downstream of Zêzere river (S. Francisco de Assis and Barroca do Zêzere) were classified as environmentally exposed (16 males and 25 females). The 41 male miners and ex-miners from the Panasqueira mine represented the group of occupationally exposed. Whereas 40 additional subjects without environmental and/or occupational exposure to mining activities, or other known toxic exposure, were the controls. The control group included individuals living in non contaminated areas upstream the river and on the western side of the mine (Casegas and Unhais-o-Velho). The individuals in the control group worked mainly in administrative offices and were matched with the environmentally exposed group by age, gender, lifestyle, and smoking habits (17 males and 23 females). The criteria used to select the individuals for the study were age over 18 years and living in the same village for at least 5 years before the study. A questionnaire was used to assess the personal health status, medical history, medication, diagnostic tests (X-rays, etc.), and lifestyle factors. All subjects were fully informed about the procedures and objectives of this study, and signed an informed consent form. Approval for this study was obtained from the Institutional Ethical Board of the Portuguese National Institute of Health.

\subsection{Sample collection}

Blood samples were collected by venipuncture in BD Vacutainer ${ }^{\circledR}$ СРТ ${ }^{\mathrm{TM}}$ tubes with sodium heparin for mononuclear leukocytes isolation prior to TCR mutation and comet assays, and in tubes containing sodium heparin for cytokinesis block MN test, CA, and for genetic polymorphism analysis.
Samples were transported under refrigeration and stored at approximately $+4{ }^{\circ} \mathrm{C}$ until mononuclear leukocyte isolation and analysis for MN test and CA, and at- $-20{ }^{\circ} \mathrm{C}$ for DNA extraction and genotyping. All samples were coded and analysed under blind conditions.

\subsection{TCR mutation assay}

Isolation of mononuclear leukocytes was performed using BD Vacutainer ${ }^{\circledR}$ СРТ ${ }^{\mathrm{TM}}$ tubes, following manufacturer's instructions. The mononuclear leukocyte layer (buffy coat) was removed and washed three times with ice-cold phosphate buffer solution (PBS) of $\mathrm{pH} 7.4$, at $1000 \mathrm{rpm}(\sim 270 \times \mathrm{g})$ for $10 \mathrm{~min}$. TCR mutation assay was carried out with flow cytometry according to García-Lestón et al. (2011).

\subsection{Comet assay}

Mononuclear leukocytes were isolated as described in the TCR mutation assay protocol. Cells were suspended in freezing medium ( $50 \%$ foetal calf serum, 40\% RPMI 1640, 10\% DMSO) to obtain $10^{7}$ cells $/ \mathrm{mL}$, and stored at $-80{ }^{\circ} \mathrm{C}$ until the time of analysis. The mononuclear leukocytes were quickly thawed at $37{ }^{\circ} \mathrm{C}$. Cell viability was assessed by trypan blue exclusion technique where in all cases it was found to be higher than $85 \%$. The alkaline version of the comet assay was performed as described by Costa et al. (2008) with a number of modifications. Briefly, cells were suspended in $100 \mu \mathrm{L}$ low melting point agarose and dropped ( $5 \mu \mathrm{L}$ drops -4 drops per individual, 12 drops per slide) onto a frosted slide precoated with normal melting point agarose. After lysis, unwinding and electrophoresis the slides were washed with PBS 7.4 and ice-cold bi-distilled water. They were then further dehydrated in ethanol solutions (70\% and 96\%). Prior to analysis, gels were stained with SYBR Green solution, washed twice with ice-cold bi-distilled water and left to dry for 30-60 min. Before each slide was scored a drop of water and a cover slip were placed on top of them. Twenty-five randomly selected cells from each gel (100 cells/donor) were examined.

\subsection{Cytokinesis-block MN test}

Aliquots of $0.5 \mathrm{~mL}$ heparinised whole blood were used to establish duplicate lymphocyte cultures for cytokinesis-block MN test, as described in Costa et al. (2006). To determine the total number of MN in binucleated cells, a total of 1000 binucleated cells with wellpreserved cytoplasm (500 per replicate) were scored for each subject. MN was scored by the same reader and identified according to the criteria defined by Fenech (2007).

\subsection{CA assay, aneuploidies and gaps}

Duplicate lymphocyte cultures for CA were established using $0.5 \mathrm{~mL}$ of heparinised whole blood as described in Roma-Torres et al. (2006). One hundred metaphases were analysed for each individual, and fifty from each duplicate culture, according to the criteria of Therman (1980).

Metaphases with 46 chromosomes were scored. The structural aberrations were classified as follows: Total CA frequency (CA-total) was defined as the number of aberrations, excluding gaps; Chromosometype aberrations (CA-chromosome) included chromosome-type breaks, ring chromosomes, and dicentrics; Chromatid type aberrations (CAchromatid) included chromatid-type breaks. Aneuploidies (cells with 45 and 47 chromosomes) and gaps (single and double) were also scored. 


\subsection{DNA extraction and genotyping}

Genomic DNA was obtained from $200 \mu \mathrm{L}$ of heparinised whole blood samples using a commercially available kit according to the manufacturer's instructions (QIAamp DNA extraction kit - Qiagen, Hilden, Germany). Each DNA sample was stored at $-20{ }^{\circ} \mathrm{C}$ until analysis.

The GSTA2 Ser112Thr (rs2180314) polymorphism was genotyped by real-time PCR (AB7300) using TaqMan ${ }^{\circledR}$ SNP Genotyping Assays from Applied Biosystems (ABI Assays reference: C_22275149_30) according to the manufacturer's instructions. To carry out the allelic discrimination the DNA samples were quantified by PicoGreen dsDNA Quantification Reagent (Molecular Probes, Eugene, OR, USA) according to the method of Silva et al. (2009). GSTM1 and GSTT1 analyses for gene deletions were carried out by a multiplex PCR as described by Lin et al. (1998) with minor modifications described by Teixeira et al. (2002). The GSTP1 polymorphism Ile105Val (rs1695) was determined by PCR and RFLP according to the method of Harries et al. (1997) with minor modifications described in Teixeira et al. (2004).

The XRCC1 Arg194Trp (rs1799782) and Arg399Gln (rs25487), APEX1 Asp148Glu (rs1130409), MPG Lys17Gln (rs3176383), MUTYH Gln335His (rs3219489), OGG1 Ser326Cys (rs1052133), PARP1 Val762Ala (rs1136410), PARP4 Gly1280Arg (rs13428) and Pro1328Thr (rs1050112), ERCC1 Lys504Gln (rs3212986), ERCC4 Arg415Gln (rs1800067), and ERCC5 Asp1104His (rs17655) and Cys529Ser (rs2227869) gene polymorphisms were determined by Real-Time PCR using TaqMan ${ }^{\circledR}$ SNP Genotyping Assays from Applied Biosystems (ABI Assays references: C_11463404_10, C_622564_10, C_8921503_10, C_32323403_10, C_27504565_10, C_3095552_1, C_1515368_1, C_8700143_10, C_8700142_10, C_2532948_10, C_3285104_10, C_1891743_10 and C_15956775_10, respectively) following Conde et al. (2009), Costa et al. (2008), Gomes et al. (2010), and Silva et al. (2010).

\subsection{Statistical analysis}

The three groups of exposure were compared by socio-demographic (i.e., gender, age, village of residence and years of work if miner) and lifestyle factors potentially influencing the levels of genotoxicity (i.e., smoking habits). The Chi-square test was applied for categorical variables and the analysis of variance (ANOVA) was applied for continuous variables. The effect of exposure on the level of genotoxicity biomarkers was preliminarily tested through ANOVA. To achieve a better approximation to the normal distribution, a log-transformation of the data was applied to TCR-Mf and \%DNAT. No transformation was needed for MN frequency. The Kruskal-Wallis test was performed for CA-total, CA-chromosome, CA-chromatid, and aneuploidies. Best fitting multiple regression models were used to estimate the effect of the exposure. Linear regression was applied on the log-transformed TCR-Mf and \%DNAT; negative binomial regression on non transformed data was carried out with MN and CA-total; lastly, Poisson regression on non transformed data was fitted for CA-chromosome, CA-chromatid, and aneuploidies. All models included age, smoking habit (smokers were classified as ever/never smokers given the high number of heavy smokers that declared to be ex-smokers), and actual confounders. A possible role as effect modifiers of candidate biomarkers of susceptibility on genotoxic damage induced by exposure was also tested. When the number of subjects with homozygous mutations was small, these were merged with the group of subjects with heterozygous mutations. Thus, a dominant model was hypothesised in this case; an additive model was tested in all other cases. Mean ratio (MR) was used as the point estimate of effect accompanied by its $95 \%$ confidence interval (CI). To take into account the village of origin and to evaluate the accumulation of exposure from the work and the environment, the occupationally exposed population was divided into: i) subjects occupationally and environmentally exposed (working in the mine and living in villages near the mine); and ii) subjects only occupationally exposed, (working in the mine and living in villages upstream the river). Linear regression on log-TCR-Mf and log-\%DNAT, and negative binomial regression on CA-total were fitted to estimate the effect of exposure according to these new groups. Adjustment for age, smoking habit and parameter-specific actual confounders was applied. An ancillary analysis was carried out to quantitatively assess the association between metal(loid) concentration and genotoxicity. The study subjects were divided into three groups according to the tertile distribution of each metal(loid). The resulting three-level factors [one factor for each metal(loid)] were, in turn, fitted in a regression model on the genotoxicity biomarkers. For each biomarker, the best fitting regression method was chosen. All models included age, smoking habits, and model-specific confounders. The critical limit for significance was set at $P<0.05$. The statistical software used for the analyses were StataCorp. 2011, Stata Statistical Software: Release 12, College Station, TX: StataCorp LP and SPSS Inc. Released 2004, SPSS for Windows, Version 13, Chicago, SPSS Inc.

\section{Results}

General characteristics of the study populations are summarised in Table 1 . The group of occupationally exposed subjects was composed by males only, and differed also from the others because of the much higher proportion of smokers.

Univariate comparisons of genotoxicity biomarkers by study group are reported in Table 2. Significant differences were found for all biomarkers except for the frequency of aneuploidies (47), with higher values in the exposed groups, particularly in the environmentally exposed.

The genotoxic effect of exposure, age, and smoking habits, adjusted for the presence of confounding factors, was evaluated with multivariable modelling (Table 3). Significant increases observed in exposed groups when compared to controls confirmed the result of univariate analysis, with the only exception of MN which did not show any significant differences. The environmentally exposed group showed significantly higher \%DNAT, CA-total, CA-chromosome and CA-chromatid when compared to the control group. The occupationally exposed group showed significantly higher TCR-Mf and \%DNAT. Significant effect

Table 1

Description of the study population.

\begin{tabular}{|c|c|c|c|c|}
\hline Variable & Controls & $\begin{array}{l}\text { Environmentally } \\
\text { exposed }\end{array}$ & $\begin{array}{l}\text { Occupationally } \\
\text { exposed }\end{array}$ & $\begin{array}{l}P \\
\text { value }\end{array}$ \\
\hline Total & 40 & 41 & 41 & \\
\hline $\begin{array}{l}\text { Duration of work } \\
\text { (years, current } \\
\text { miners) }{ }^{\mathrm{a}}\end{array}$ & - & - & $25.07 \pm 7.07$ & \\
\hline Ex-miners & & & 34 & \\
\hline $\begin{array}{l}\text { Duration of work } \\
(\text { years) })^{\mathrm{a}}\end{array}$ & - & - & $18.30 \pm 10.19$ & \\
\hline $\begin{array}{l}\text { Time since stop } \\
\text { working (years) }\end{array}$ & - & - & $16.25 \pm 18.13$ & \\
\hline \multicolumn{5}{|l|}{ Village } \\
\hline S. Francisco de Assis & $0(0 \%)$ & $19(46 \%)$ & $9(22 \%)$ & $<0.001^{\mathrm{b}}$ \\
\hline Casegas & $16(40 \%)$ & $0(0 \%)$ & $0(0 \%)$ & \\
\hline Barroca do Zêzere & $0(0 \%)$ & $22(54 \%)$ & $8(19 \%)$ & \\
\hline Unhais-o-Velho & $24(60 \%)$ & $0(0 \%)$ & $24(59 \%)$ & \\
\hline \multicolumn{5}{|l|}{ Gender } \\
\hline Female & $23(59 \%)$ & $25(61 \%)$ & $0(0 \%)$ & $<0.001^{\mathrm{b}}$ \\
\hline Male & $17(43 \%)$ & $16(39 \%)$ & $41(100 \%)$ & \\
\hline \multicolumn{5}{|l|}{ Age (years) ${ }^{\mathrm{a}}$} \\
\hline & $\begin{array}{l}56.60 \pm \\
12.58\end{array}$ & $61.71 \pm 13.5$ & $62.05 \pm 7.57$ & $0.063^{\mathrm{c}}$ \\
\hline \multicolumn{5}{|l|}{ Smoking habits } \\
\hline Never smokers & $25(62 \%)$ & $32(78 \%)$ & $16(39 \%)$ & $0.001^{\mathrm{b}}$ \\
\hline Ever smokers & $15(38 \%)$ & $9(22 \%)$ & $25(61 \%)$ & \\
\hline
\end{tabular}

a Mean \pm standard deviation.

b Chi-square test.

c ANOVA test. 
Table 2

Levels of genotoxicity biomarkers in the study groups.

\begin{tabular}{|c|c|c|c|c|c|c|c|}
\hline & \multicolumn{2}{|c|}{ Controls } & \multicolumn{2}{|c|}{ Environmentally exposed } & \multicolumn{2}{|c|}{ Occupationally exposed } & \multirow[b]{2}{*}{$P$ value $^{\mathrm{a}}$} \\
\hline & $\mathrm{N}$ & Mean $\pm S D$ & $\mathrm{~N}$ & Mean \pm SD & $\mathrm{N}$ & Mean $\pm S D$ & \\
\hline TCR-Mf $\left(10^{-4}\right)$ & 39 & $3.80 \pm 2.11$ & 34 & $4.92 \pm 3.86$ & 38 & $5.80 \pm 3.93$ & 0.018 \\
\hline$\%$ DNAT & 40 & $12.40 \pm 3.04$ & 41 & $24.58 \pm 7.75$ & 41 & $18.73 \pm 7.60$ & $<0.001$ \\
\hline MN (\%) & 40 & $6.45 \pm 4.47$ & 41 & $8.46 \pm 5.27$ & 41 & $4.98 \pm 3.06$ & 0.002 \\
\hline CA-total & 40 & $2.65 \pm 2.11$ & 41 & $5.56 \pm 2.92$ & 41 & $3.24 \pm 2.45$ & $<0.001$ \\
\hline CA-chromosome_type & 40 & $0.55 \pm 1.04$ & 41 & $1.22 \pm 1.39$ & 41 & $0.71 \pm 1.10$ & 0.018 \\
\hline CA-chromatid_type & 40 & $2.10 \pm 1.52$ & 41 & $4.34 \pm 2.56$ & 41 & $2.54 \pm 1.90$ & $<0.001$ \\
\hline Aneuploidies (45) & 40 & $1.65 \pm 1.46$ & 41 & $3.32 \pm 1.77$ & 41 & $2.66 \pm 1.51$ & $<0.001$ \\
\hline Aneuploidies (47) & 40 & $0.13 \pm 0.33$ & 41 & $0.20 \pm 0.46$ & 41 & $0.32 \pm 0.57$ & 0.221 \\
\hline Gaps-single & 40 & $0.83 \pm 1.03$ & 41 & $2.15 \pm 1.86$ & 41 & $1.39 \pm 1.51$ & 0.001 \\
\hline Gaps-double & 40 & $0.00 \pm 0.00$ & 41 & $0.37 \pm 0.54$ & 41 & $0.17 \pm 0.44$ & $<0.001$ \\
\hline
\end{tabular}

a ANOVA test.

of age was observed for TCR-Mf in the 61-70 years age-group and also for \%DNAT in individuals older than 71 years $(>71)$. No significant effect of smoking habits was observed on any biomarker. Higher mean ratios (MR) were generally observed in individuals living in the polluted villages than in those who worked in the mine.

The effect of gender was evaluated only in the group of exposed residents and in controls, since miners were only males. Only MN frequency was influenced by this factor, with exposed females showing significantly higher frequencies than males in controls (MR: 1.78; 95\% CI: 1.17-2.70) and in the environmentally exposed group (MR: $1.51 ; 95 \% \mathrm{CI}: 1.17-2.70$ ). The effect of exposure in this biomarker was revealed by the increased MR in females environmentally exposed as compared to non exposed females (MR: 1.41; 95\% CI: 1.00-1.97). No significant differences between males were observed.

The presence of synergy between occupational and environmental exposure was evaluated comparing miners living in polluted villages vs. those living in villages upstream the mine. No biomarker showed higher frequency in the group of subjects exposed to metal(loid)s from both sources (data not shown).

To evaluate the effect of metal(loid) concentration on the selected biomarkers we used measure of individual exposure for our subjects available from the study mentioned above (Coelho et al., in press). Subjects were divided according to the tertile distribution of each metal(loid) level, in all biological matrices analysed (blood, urine, hair, fingernails, and toenails). Most specific results were obtained for As, $\mathrm{Mn}$ and $\mathrm{Pb}$ in toenails (TN) (Table 4). Levels of As in the 3rd tertile were significantly associated with the levels of \%DNAT, MN, CA-total, CA-chromosome, and CA-chromatid. Mn levels in the 3rd tertile determined a significant increase of MN, CA-total and CA-chromosome.
Higher levels of $\mathrm{Pb}$ were generally associated with higher frequencies of CA-total, CA-chromosome and CA-chromatid.

The influence of several polymorphisms of genes encoding for metabolic and DNA repair enzymes on the level of genotoxicity markers was evaluated and statistically significant results are gathered in Table 5. The wild type homozygous or positive (in the case of GSTM1) genotypes were always the reference category. CA-total and CAchromosome MRs increased in the GSTM1 positive exposed individuals; the increases were more pronounced in the environmentally exposed group. Besides, a significantly higher mean of the CA-chromosome MRs was observed in the null control group. GSTM1 null exposed individuals showed significant decreases in the CA-total and CA-chromosome MRs . A significant increase in the mean \%DNAT ratio was observed in the homozygous wild type subjects for APEX1 polymorphism from the environmentally exposed group, and in $T G$ heterozygous individuals from the occupationally exposed group. CA-total and CA-chromatid MRs were significantly increased in the OGG1 homozygous wild type exposed groups and in the control individuals carrying the $G$ variant allele. Also, the same parameters were significantly reduced in occupationally exposed $G$ allele carriers. The ERCC1 genotypes influenced the \%DNAT MR in the environmentally exposed group ( $G G$ and $G T+T T$ ), and in the occupationally exposed individuals carrying the $T$ variant allele. Similarly to what has been observed for GSTM1, ERCC1 genotypes showed significantly increases of CA-chromosome MR in environmentally exposed homozygous wild type individuals and an opposite trend in controls, where $T$ allele carriers show higher frequencies. Finally, CAchromatid MR significantly increased in environmentally exposed wild type homozygotes for ERCC4 polymorphism, while environmentally exposed individuals with the $A$ variant allele showed lower frequencies for CA-chromatid $(P<0.01)$ and $M N(P=0.051)$.

Table 3

Effect of exposure, age and smoking habits on the biomarkers of genotoxicity. Adjustment for age, smoking and genotoxicity parameter-specific actual confounders.

\begin{tabular}{|c|c|c|c|c|c|c|c|c|c|c|c|c|}
\hline & \multicolumn{2}{|c|}{ TCR-Mf } & \multicolumn{2}{|l|}{ \%DNAT } & \multicolumn{2}{|l|}{ MN } & \multicolumn{2}{|c|}{ CA-total } & \multicolumn{2}{|c|}{ CA-chromosome } & \multicolumn{2}{|c|}{ CA-chromatid } \\
\hline & MR & $95 \% \mathrm{CI}$ & MR & $95 \% \mathrm{CI}$ & MR & $95 \% \mathrm{CI}$ & MR & $95 \% \mathrm{CI}$ & MR & $95 \% \mathrm{CI}$ & MR & $95 \% \mathrm{CI}$ \\
\hline \multicolumn{13}{|l|}{ Exposure } \\
\hline Controls $(\mathrm{N}=40)$ & 1.00 & & 1.00 & & 1.00 & & 1.00 & & 1.00 & & 1.00 & \\
\hline Env. exposed $(\mathrm{N}=41)$ & 0.99 & $(0.75,1.32)$ & $1.78^{* *}$ & $(1.54,2.06)$ & 1.21 & $(0.89,1.64)$ & $2.15^{* *}$ & $(1.57,2.93)$ & $2.68^{* *}$ & $(1.52,4.72)$ & $2.05^{* *}$ & $(1.53,2.73)$ \\
\hline Occup. exposed $(\mathrm{N}=41)$ & $1.38^{*}$ & $(1.04,1.82)$ & $1.45^{* *}$ & $(1.25,1.68)$ & 0.75 & $(0.54,1.02)$ & 1.12 & $(0.81,1.56)$ & 1.23 & $(0.67,2.26)$ & 1.24 & $(0.91,1.69)$ \\
\hline \multicolumn{13}{|l|}{ Age (years) } \\
\hline $25-50(\mathrm{~N}=23)$ & 1.00 & & 1.00 & & 1.00 & & 1.00 & & 1.00 & & 1.00 & \\
\hline $51-60(\mathrm{~N}=35)$ & 1.30 & $(0.93,1.82)$ & 0.96 & $(0.80,1.14)$ & 1.35 & $(0.92,1.99)$ & 1.20 & $(0.82,1.77)$ & 1.73 & $(0.90,3.31)$ & 1.09 & $(0.75,1.58)$ \\
\hline $61-70(\mathrm{~N}=38)$ & $1.78^{* *}$ & $(1.28,2.48)$ & 1.13 & $(0.95,1.34)$ & 1.17 & $(0.80,1.68)$ & 1.20 & $(0.84,1.72)$ & 1.04 & $(0.57,1.91)$ & 1.24 & $(0.87,1.76)$ \\
\hline$>71(\mathrm{~N}=26)$ & 1.28 & $(0.89,1.83)$ & $1.30^{* *}$ & $(1.09,1.56)$ & 1.14 & $(0.77,1.68)$ & 1.27 & $(0.87,1.87)$ & 0.94 & $(0.47,1.88)$ & 1.30 & $(0.92,1.84)$ \\
\hline \multicolumn{13}{|l|}{ Smoking habits } \\
\hline Never smokers $(\mathrm{N}=73)$ & 1.00 & & 1.00 & & 1.00 & & 1.00 & & 1.00 & & 1.00 & \\
\hline Ever smokers $(\mathrm{N}=49)$ & 0.88 & $(0.69,1.12)$ & 1.09 & $(0.96,1.23)$ & 0.81 & $(0.61,1.07)$ & 1.13 & $(0.87,1.48)$ & 1.02 & $(0.64,1.62)$ & 1.21 & $(0.94,1.56)$ \\
\hline
\end{tabular}

* $P<0.05$.

** $P<0.01$. MR - Mean Ratio 
Table 4

Effect of the levels of As, Mn, and $\mathrm{Pb}$ in toenails on the genotoxicity parameters. Estimates adjusted for age, smoking and genotoxicity parameter-specific actual confounders.

\begin{tabular}{|c|c|c|c|c|c|c|c|c|c|c|c|c|}
\hline & \multicolumn{2}{|c|}{ TCR-Mf } & \multicolumn{2}{|l|}{ \%DNAT } & \multicolumn{2}{|l|}{ MN } & \multicolumn{2}{|c|}{ CA-total } & \multicolumn{2}{|c|}{ CA-chromosome } & \multicolumn{2}{|c|}{ CA-chromatid } \\
\hline & MR & $95 \% \mathrm{CI}$ & MR & $95 \% \mathrm{CI}$ & MR & $95 \% \mathrm{CI}$ & MR & $95 \% \mathrm{CI}$ & MR & $95 \% \mathrm{CI}$ & MR & $95 \% \mathrm{CI}$ \\
\hline \multicolumn{13}{|l|}{ As } \\
\hline 1st tertile & 1.00 & & 1.00 & & 1.00 & & 1.00 & & 1.00 & & 1.00 & \\
\hline 2nd tertile & 0.86 & $(0.75,1.32)$ & 1.03 & $(0.88,1.21)$ & $1.13_{* *}$ & $(0.84,1.53)$ & $1.16_{* *}$ & $(0.83,1.62)$ & 2.07 & $(0.90,4.78)$ & 1.06 & $(0.75,1.49)$ \\
\hline 3rd tertile & 0.96 & $(1.04,1.82)$ & $1.42^{* *}$ & $(1.22,1.66)$ & $1.67^{* *}$ & $(1.28,2.20)$ & $1.96^{* *}$ & $(1.44,2.68)$ & $4.57^{* *}$ & $(2.10,9.95)$ & $1.57^{* *}$ & $(1.14,2.17)$ \\
\hline \multicolumn{13}{|l|}{ Mn } \\
\hline 1st tertile & 1.00 & & 1.00 & & 1.00 & & 1.00 & & 1.00 & & 1.00 & \\
\hline 2nd tertile & 1.08 & $(0.81,1.45)$ & 1.01 & $(0.84,1.21)$ & 1.23 & $(0.95,1.71)$ & 1.32 & $(0.94,1.86)$ & 1.71 & $(0.82,3.56)$ & 1.09 & $(0.78,1.54)$ \\
\hline 3rd tertile & 1.02 & $(0.76,1.38)$ & 1.18 & $(0.99,1.40)$ & $1.41^{* *}$ & $(1.07,1.87)$ & $1.72^{*}$ & $(1.22,2.41)$ & $2.18^{* *}$ & $(1.05,4.51)$ & 1.31 & $(0.95,1.82)$ \\
\hline \multicolumn{13}{|l|}{$\mathrm{Pb}$} \\
\hline 1st tertile & 1.00 & & 1.00 & & 1.00 & & 1.00 & & 1.00 & & 1.00 & \\
\hline 2nd tertile & 1.05 & $(0.93,1.82)$ & 1.11 & $(0.93,1.34)$ & 1.25 & $(0.92,1.71)$ & $1.54^{* *}$ & $(1.10,2.16)$ & 1.93 & $(0.89,4.18)$ & $1.49^{*}$ & $(1.05,2.12)$ \\
\hline 3rd tertile & 1.36 & $(0.99,1.89)$ & 1.11 & $(0.92,1.33)$ & 1.16 & $(0.86,1.56)$ & $1.43^{*}$ & $(2.00,1.03)$ & $2.58^{* *}$ & $(1.26,5.30)$ & 1.24 & $(0.87,1.75)$ \\
\hline
\end{tabular}

$* P<0.05$.

** $P<0$ 0.01.Mean Ratio.

\section{Discussion}

The results obtained in the environmental geochemical campaigns performed near Panasqueira mine reported a high degree of contamination by several metal(loid)s (Ávila et al., 2008; Ferreira da Silva et al., 2013; Grangeia et al., 2011; Salgueiro et al., 2008). These findings were implemented by biomonitoring studies which found higher concentrations of metal(loid)s, such as As, Cr, Mn,
$\mathrm{Mo}, \mathrm{Pb}$ and $\mathrm{Zn}$ in the blood, urine, nails, and hair of people living near or working in the mine (Coelho et al., in press). Preliminary data showing increased genotoxic damage in these populations are also available (Coelho et al., 2011, 2012). The present study with a more robust design was aimed to evaluate the genotoxic damage caused by this contamination and the possible influence of a set of genetic polymorphisms. For this purpose several biomarkers of genotoxicity were analysed, including the frequencies of TCR

Table 5

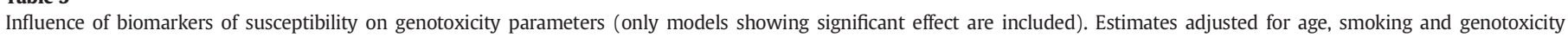
parameter-specific actual confounders.

\begin{tabular}{|c|c|c|c|c|c|c|c|c|c|}
\hline & \multicolumn{3}{|c|}{ Control } & \multicolumn{3}{|c|}{ Environmentally exposed } & \multicolumn{3}{|c|}{ Occupationally exposed } \\
\hline & $\mathrm{N}$ & MR & $(95 \% \mathrm{CI})$ & $\mathrm{N}$ & MR & $(95 \% \mathrm{CI})$ & $\mathrm{N}$ & MR & $(95 \% \mathrm{CI})$ \\
\hline \multicolumn{10}{|c|}{ GSTM1 deletion } \\
\hline \multicolumn{10}{|c|}{ CA-total } \\
\hline Positive & 16 & 1 & & 14 & $2.31^{*}$ & $(1.44,3.70)$ & 14 & $1.78^{*}$ & $(1.11,2.86)$ \\
\hline Null & 24 & 1.11 & $(0.71,1.75)$ & 27 & 0.90 & $(0.50,1.60)$ & 27 & $0.46^{*}$ & $(0.25,0.85)$ \\
\hline \multicolumn{10}{|c|}{ CA-chromosome } \\
\hline Positive & 16 & 1 & & 14 & $7.17^{* *}$ & $(2.38,21.62)$ & 14 & $3.88^{*}$ & $(1.26,11.60)$ \\
\hline Null & 24 & $3.02^{*}$ & $(1.01,9.04)$ & 27 & $0.25^{*}$ & $(0.07,0.87)$ & 27 & $0.16^{*}$ & $(0.04,0.61)$ \\
\hline \multicolumn{10}{|c|}{ APEX1 rs1130409 } \\
\hline \multicolumn{10}{|c|}{ \%DNAT } \\
\hline TT & 11 & 1 & & 12 & $1.91^{* *}$ & $(1.48,2.46)$ & 12 & 1.22 & $(0.94,1.57)$ \\
\hline$T G$ & 14 & 1.02 & $(0.80,1.29)$ & 15 & 0.83 & $(0.60,1.16)$ & 15 & $1.40^{*}$ & $(1.01,1.95)$ \\
\hline GG & 15 & 0.90 & $(0.71,1.13)$ & 14 & 1.01 & $(0.72,1.41)$ & 14 & 1.13 & $(0.81,1.58)$ \\
\hline \multicolumn{10}{|c|}{ OGG1 rs1052133 } \\
\hline \multicolumn{10}{|c|}{ CA-Total } \\
\hline$C C$ & 23 & 1 & & 28 & $2.58^{* *}$ & $(1.74,3.84)$ & 24 & $1.79^{* *}$ & $(1.17,2.74)$ \\
\hline$C G+G G$ & 17 & $1.81^{*}$ & $(1.15,2.86)$ & 13 & 0.70 & $(0.40,1.24)$ & 17 & $0.34^{* *}$ & $(0.18,0.65)$ \\
\hline \multicolumn{10}{|c|}{ CA-chromatid } \\
\hline$C C$ & 23 & 1 & & 28 & $2.38^{* *}$ & $(1.64,3.47)$ & 24 & $1.84^{* *}$ & $(1.22,2.76)$ \\
\hline$C G+G G$ & 17 & $1.65^{*}$ & $(1.04,2.61)$ & 13 & 0.75 & $(0.43,1.31)$ & 17 & $0.33^{* *}$ & $(0.17,0.61)$ \\
\hline \multicolumn{10}{|c|}{ ERCC1 rs3212986 } \\
\hline \multicolumn{10}{|c|}{ \%DNAT } \\
\hline GG & 23 & 1 & & 21 & $1.48^{* *}$ & $(1.24,1.77)$ & 16 & 1.19 & $(0.99,1.43)$ \\
\hline$G T+T T$ & 17 & 0.93 & $(0.78,1.13)$ & 20 & $1.47^{* *}$ & $(1.13,1.89)$ & 25 & $1.44^{* *}$ & $(1.11,1.87)$ \\
\hline \multicolumn{10}{|c|}{ CA-chromosome } \\
\hline GG & 23 & 1 & & 21 & $5.29^{* *}$ & $(2.22,12.62)$ & 16 & 1.08 & $(0.36,3.23)$ \\
\hline$G T+T T$ & 17 & $2.62^{*}$ & $(1.02,6.73)$ & 20 & $0.27^{*}$ & $(0.09,0.81)$ & 25 & 0.91 & $(0.24,3.42)$ \\
\hline \multicolumn{10}{|c|}{ ERCC4 rs 1800067} \\
\hline \multicolumn{10}{|c|}{$\mathrm{MN}$} \\
\hline GG & 29 & 1 & & 30 & 1.42 & $(1.00,2.01)$ & 30 & 0.76 & $(0.53,1.09)$ \\
\hline$G A+A A$ & 11 & 1.13 & $(0.73,1.75)$ & 11 & 0.53 & $(0.28,1.00)$ & 11 & 0.96 & $(0.50,1.85)$ \\
\hline \multicolumn{10}{|c|}{ CA-chromatid } \\
\hline GG & 29 & 1 & & 30 & $2.51^{* *}$ & $(1.78,3.54)$ & 30 & 1.29 & $(0.90,1.84)$ \\
\hline$G A+A A$ & 11 & 1.02 & $(0.61,1.72)$ & 11 & $0.49^{*}$ & $(0.25,0.98)$ & 11 & 0.94 & $(0.48,1.87)$ \\
\hline
\end{tabular}

* $P<0.05$.

** $P<0$ 0.01.MR - Mean Ratio. 
mutation, MN, and CA, and DNA damage revealed by comet assay (\%DNAT), and genetic susceptibility was evaluated by genotyping several polymorphisms of genes encoding for enzymes involved in the metabolism of metal(loid)s and DNA repair process. A significant increase in most biomarkers of genotoxicity was found in exposed populations. Genotoxic damage was found in exposed populations even after adjustment for confounding factors except for MN. For this biomarker the effect of exposure was only evident in females.

To understand the mechanism leading to the observed effects, several features have to be taken into account. These features are the source of exposure (environmental/occupational), the information given by each biomarker in terms of time frame of exposure and type of damage, and the specific metal(loid) evaluated. The increase in TCR-Mf appears to be associated with occupational exposure. Whereas the DNA damage (comet assay) was higher with both sources but more intensely with the environmental exposure. Lastly, the higher frequency of MN (only in females) and CA seems to be related to environmental exposure.

Each biomarker reflects different time frame of exposure. Cytogenetic alterations detected by $\mathrm{CA}$ and $\mathrm{MN}$ reflect exposures that may have been experienced in the few months before sample collection, although exposure in the previous 2-3 years or even in a much longer period may affect these biomarkers (Liu et al., 2010). Mutations detected by the TCR mutation assay reflect exposures experienced during a period of months to 2-3 years before sampling (Taooka et al., 2006). The comet assay provides information on more recent exposures (few hours/days) and reflects a type of damage that is easily repairable. The use of different matrices, such as blood, urine, hair, fingernails and toenails provides additional information. This is used to interpret the association between exposure and early biological effects in terms of time frame. The blood and urine samples generally reflect recent exposures such as days to few weeks. Whereas hair, nails, and particularly toenails reflect exposures occurring in the last weeks to months. The differences between recent and past exposures for some elements, such as $\mathrm{Cd}$ and $\mathrm{Pb}$ may be not straightforward as these accumulate in the human body for years. However, the combination of results from all the matrices allows a better understanding of the effects of each type of exposure.

As described in Coelho et al. (in press) the two exposed groups have different types of exposure. The environmentally exposed group experienced a pronounced and continuous (past and recent) exposure to As, a moderate but continuous exposure to $\mathrm{Mg}$, Mn and $\mathrm{Zn}$, a recent exposure to Mo and past exposure to $\mathrm{Cr}$, Ni and $\mathrm{S}$. The occupationally exposed group experienced a continuous exposure to $\mathrm{Zn}$, recent exposure to Se, and long standing exposure to As, $\mathrm{Mn}$ and $\mathrm{Pb}$. Additionally when we evaluated the genotoxic effect of metal(loid) concentration according to their tertile distribution, significant results were obtained for $\mathrm{As}, \mathrm{Mn}$ and $\mathrm{Pb}$ for the majority of the matrices, particularly toenails which presented several significant differences in the two higher tertiles (Table 4). Considering all the previous factors, we can say that our results seem to point to environmental exposure to As (mainly) and $\mathrm{Mn}$ as the main conditions inducing genotoxic damage at short term (high levels of DNA damage - \%DNAT) and medium-long term (increased frequencies of MN and CA). Similarly, although with a lower degree of evidence, occupational exposure to $\mathrm{As}, \mathrm{Mn}$, and $\mathrm{Pb}$ appeared to induce genotoxic damage at short term level (high \%DNAT), and at medium term (increased TCR-Mf). The increase in TCR-Mf seems to be associated with exposure to $\mathrm{Pb}$ as significant increases in the mutation frequency were observed in the second and third tertiles for blood and hair $\mathrm{Pb}$ contents, and in the highest tertile for toenails $(P=0.060)$. GarciaLestón and co-workers have an extensive work on this field and they also found a significant increase in TCR-Mf due to occupational exposure to Pb (García-Lestón et al., 2010, 2011, 2012).
The major effects of the confounding factors were observed for age in the TCR-Mf and in the \%DNAT, with significantly higher levels in older groups, and for gender in the MN frequency, with significantly higher frequencies in females. The effect of age on TCR-Mf has been previously described. Akiyama et al. (1995) found a significant increase in TCR-Mf associated with age (increasing $2 \times 10^{-5}$ for every 10 years of age). The rise in mutation frequency is due to errors associated with DNA replication in each cell division, so the mutation frequency increases in proportion to the number of cell divisions and, in addition, the efficiency of the DNA repair processes decreases with age.

A comprehensive paper published by Möller (2006) describes the presence of association between age and the basal level of DNA damage reporting a significant increase in the levels of this damage in older individuals. This is quantified by comet assay for various age levels. Besides, there are several studies reporting an association between gender and cytogenetic damage detected by MN frequency. Bonassi et al. (1995) found that the MN frequencies in females were 20-30\% higher than males. This finding may be attributed to preferential aneugenic events involving the X chromosome (Barale et al., 1998; Surrallés et al., 1996). To take into account the potential effect of these parameters on the association between exposure and genotoxic damage all regression models used in this analysis included age and gender as potential confounder or effect modifier.

Polymorphic genes involved in the metabolism of contaminants may modulate the extent of damage due to environmental and/or occupational exposure to genotoxic agents (Pavanello and Clonfero, 2000). The identification of genetic polymorphisms which have a key role in modulating genetic damage can help to minimise risks for susceptible subjects (Costa et al., 2008). In the present study we found a significant influence of GSTM1 on the effect of exposure to genotoxic agents. This polymorphic gene has been extensively studied, as individuals presenting the null genotype have a decreased ability to detoxify carcinogens, thus having a higher sensitivity to genetic damage and an increased cancer risk (Rossi et al., 2009). Accordingly, our results showed among the control group a higher CA-chromosome MR in the GSTM1 null individuals. On the other hand, the effect of this genotype on the presence of exposure was the opposite i.e. lower CA-total and CA-chromosome MRs . Two of the major studies which evaluated the influence of GSTM1 deletion on CA frequencies were performed by Rossi et al. (2009) and Skjelbred et al. (2011). None of these studies, that investigated cancer cases vs. control individuals and a population of healthy individuals, respectively, found any significant effect of these modifications.

DNA repair mechanisms are vital responses to multiple types of DNA damage, specifically those from exposure to environmental and endogenous carcinogens (McWilliams et al., 2008). Genetic variations in DNA repair genes may modulate DNA repair capacity and, therefore influence risk for development of cancer and other mutation related diseases (Kiyohara and Yoshimasu, 2007). As regards the DNA repair genotypes analysed, significant influences were found for APEX1 rs1130409, OGG1 rs1052133, ERCC1 rs3212986, and ERCC4 rs1800067. The APEX1 gene encodes the major apurinic/apyrimidinic (AP) endonuclease and has a major role in the BER of DNA damage (Shen et al., 2005). A significant increase in the DNA damage MR was found in both exposed groups in individuals carrying the $T$ allele. This result is in agreement with evidence supporting an association between the $G$ allele and lower levels of DNA damage with a consequent decreased risk of a number of human cancers (Yu et al., 2012). The human OGG1 gene encodes a protein responsible for excision of 8-oxoGua, the main base lesion caused by oxidative damage to DNA. If the lesion is not repaired, it can pair with adenine leading to a GC to TA transversion. Significant influence of exposure on CAtotal and CA-chromatid was observed in all exposed individuals wild type homozygous, as well as in the control carriers of the 
variant $G$ allele. The vast majority of studies report a lower ability of the $G$ allele to repair DNA damage and consequently this genotype should increase mutagenic events (Bravard et al., 2009; Yamane et al., 2004). Our results also showed a combined effect of exposure and genotype in occupationally exposed people carrying the variant $G$ allele, although these findings go in the opposite direction i.e. decreases in the MRs. With regard to this result, it has been suggested that the effect of this polymorphism on DNA repair capacity may differ with the type and extent of exposure and can be influenced by the interaction with other genetic polymorphisms (Mateuca et al., 2008). The excision repair cross-complementing (ERCC) gene family reduces damage to DNA via NER. The ERCC1 gene encodes a protein that, along with ERCC4, functions in a complex involved in the $5^{\prime}$ incision made during NER process (van Vuuren et al., 1995). Our results for this polymorphism showed significant combined effect with exposure in both exposed groups concerning \%DNAT (increases in the MR), and only in the environmentally exposed group for CA-chromosome (decrease in the MR). These contrasting results might be in part explained by the different genotoxic endpoint detected by these assays. The number of reports analysing the effect of this polymorphism is scarce. Costa et al. (2008) did not find a significant influence in any of the genotoxicity biomarkers studied, whereas Zienolddiny et al. (2006) found $T$ allele to be less frequent in non-small cell lung cancer cases with higher PAH-DNA adduct levels, and speculated that individuals presenting the $T$ allele may have suboptimal DNA repair capacity. In agreement with this report the result of this study showed an increase in the CA-chromosome MR in the control individuals carrying the $T$ allele. Finally, the influence of ERCC4 polymorphism on the frequency of MN and CA-chromatid seems to be due to the protective effect of the $A$ allele (lower frequencies) in the environmentally exposed group. Also for this polymorphism fewer reports have been published. No effect was observed by Costa et al. (2008) on MN test, SCE or comet assay results. In addition, Park et al. (2002) reported no significant relationship between ERCC4 and lung cancer. Nevertheless, significant association between the $A$ allele and breast cancer risk was reported by Smith et al. (2003), particularly when in combination with the variants alleles of XRCC1 (rs1799782 and rs25487) and XRCC3 (rs861539).

The increase in genotoxicity and mutagenicity, particularly observed in susceptible individuals, is likely due to a combination of mechanisms initiated by the exposure to metal(loid)s. The possible factors are induction of oxidative stress and damage to DNA, and the presence of interferences with DNA repair systems and signal transduction pathways. A possible increase of the carcinogenic risk may be considered in this population as a consequence of these systems perturbance.

\section{Conclusions}

Overall our results are consistent with previous studies investigating the type and concentration of metal(loid)s present in the area (Coelho et al., in press; Ferreira da Silva et al., 2013). Present findings are also consistent with preliminary studies (Coelho et al., 2011; Coelho et al., 2012) pointing to increased genotoxic damage experienced by populations environmentally and occupationally exposed to metal(loid) contamination derived from the Panasqueira mine activities. To strengthen the absence of causal association between mine activities and this damage, the level of most biomarkers was quantitatively associated with the intensity of genotoxic exposure.

The extent of genetic damage associated with exposure to meta(loid)s was modulated by selected genetic polymorphisms of enzymes involved in the metabolism of metal(loid)s and DNA repair processes. Still the data is difficult to interpret and definitive conclusions on their influence cannot be reached.

In conclusion, the presence of genotoxic damage in exposed populations, their consistency with individual data of exposure, and the identification of sub-groups of susceptible populations pose a public threat that may result in an increased risk of developing cancer and other diseases. Competent authorities are urged to intervene in this area and implement preventive policies aimed to help in protecting exposed populations.

\section{Conflict of interest}

The authors declare that they have no conflicts of interest.

\section{Acknowledgements}

This work was supported by the Portuguese Foundation for Science and Technology under the grant SFRH/BD/47781/2008, and projects PTDC/SAU-OSM/105572/2008 and PTDC/SAU-ESA/102367/2008. The work of Stefano Bonassi, Valentina Dall'Armi and Roberto Zoffoli was supported by a grant funded by the Associazione Italiana per la Ricerca sul Cancro (AIRC).The authors would like to acknowledge Dr. Lisiane Meira for providing her knowledge as well as her laboratory resources for a number of experimental procedures.

\section{References}

Akiyama M, Kyoizumi S, Hirai Y, Kusunoki Y, Iwamoto KS, Nakamura N. Mutation frequency in human blood cells increases with age. Mutat Res 1995;338:141-9.

Ávila P, Silva E, Salgueiro A, Farinha J. Geochemistry and mineralogy of mill tailings impoundments from the Panasqueira mine (Portugal): implications for the surrounding environment. Mine Water Environ 2008;27:210-24.

Barale R, Chelotti L, Davini T, Del Ry S, Andreassi MG, Ballardin M, et al. Sister chromatid exchange and micronucleus frequency in human lymphocytes of 1650 subjects in an Italian population: II. Contribution of sex, age, and lifestyle. Environ Mol Mutagen 1998;31:228-42.

Bonassi S, Bolognesi C, Abbondandolo A, Barale R, Bigatti P, Camurri L, et al. Influence of sex on cytogenetic end points: evidence from a large human sample and review of literature. Cancer Epidemiol Biomarkers Prev 1995;4:671-9.

Bravard A, Vacher M, Moritz E, Vaslin L, Hall J, Epe B, et al. Oxidation status of human OGG1-S326C polymorphic variant determines cellular DNA repair capacity. Cancer Res 2009;69:3642-9.

Coelho P, García-Lestón J, Silva S, Costa C, Costa S, Coelho M, et al. Geno- and immunotoxic effects on populations living near a mine - case study: Panasqueira mine. J Toxicol Environ Health A 2011;74:1076-86.

Coelho P, Costa S, Silva S, Walter A, Ranville J, Sousa AC, et al. Metal(loid) levels in biological matrices from human populations exposed to mining contamination - Panasqueira Mine (Portugal). J Toxicol Environ Health A 2012;75:893-908.

Coelho P, Costa S, Costa C, Silva S, Walter A, Ranville J, et al. Biomonitoring of several toxic metal(loid)s in different biological matrices from environmentally and occupationally exposed populations from Panasqueira mine area - Portugal. Environ Geochem Health 2013. http://dx.doi.org/10.1007/s10653-013-9562-7.

Conde J, Silva SN, Azevedo AP, Teixeira V, Pina JE, Rueff J, et al. Association of common variants in mismatch repair genes and breast cancer susceptibility: a multigene study. BMC Cancer 2009;9:344.

Costa C. Teixeira JP, Silva S, Roma-Torres J, Coelho P, Gaspar J, et al. Cytogenetic and molecular biomonitoring of a Portuguese population exposed to pesticides. Mutagenesis 2006;21:343-50.

Costa S, Coelho P, Costa C, Silva S, Mayan O, Santos LS, et al. Genotoxic damage in pathology anatomy laboratory workers exposed to formaldehyde. Toxicology 2008;252: 40-8.

Fenech M. Cytokinesis-block micronucleus cytome assay. Nat Protoc 2007;2:1084-104.

Ferreira da Silva E, Ávila PF, Salgueiro AR, Candeias C, Garcia Pereira H. Quantitative-spatial assessment of soil contamination in S. Francisco de Assis due to mining activity of the Panasqueira mine (Portugal). Environ Sci Pollut Res 2013. http://dx.doi.org/10.1007/ s11356-013-1495-2. [online 31 January 2013].

García-Lestón J, Méndez J, Pásaro E, Laffon B. Genotoxic effects of lead: an updated review. Environ Int 2010;36:623-36.

García-Lestón J, Roma-Torres J, Vilares M, Pinto R, Cunha L, Prista J, et al. Biomonitoring of a population of Portuguese workers exposed to lead. Mutat Res 2011;721:81-8.

García-Lestón J, Roma-Torres J, Vilares M, Pinto R, Prista P, Teixeira JP, et al. Genotoxic effects of occupational exposure to lead and influence of polymorphisms in genes involved in lead toxicokinetics and in DNA repair. Environ Int 2012:43:29-36.

Gomes BC, Silva SN, Azevedo AP, Manita I, Gil OM, Ferreira TC, et al. The role of common variants of non-homologous end-joining repair genes XRCC4, LIG4 and Ku80 in thyroid cancer risk. Oncol Rep 2010;24:1079-85.

Grangeia C, Ávila P, Matias M, Ferreira da Silva E. Mine tailings integrated investigations: the case of Rio tailings (Panasqueira Mine, Central Portugal). Eng Geol 2011;123: 359-72.

Harries LW, Stubbins MJ, Forman D, Howard GC, Wolf CR. Identification of genetic polymorphisms at the glutathione S-transferase Pi locus and association with susceptibility to bladder, testicular and prostate cancer. Carcinogenesis 1997;18:641-4.

Hartwig A. Role of DNA repair inhibition in lead- and cadmium-induced genotoxicity: a review. Environ Health Perspect 1994;102:45-50. 
HERAG05 (Health Risk Assessment Guidance for Metals fact sheet 05). EurometauxICMM-Eurofer fact sheets related to effect assessment - mutagenicity. Available at: http://www.ebrc.de/industrial-chemicals-reach/projects-and-references/downloads/HERAG_FS_05_August_07.pdf, 2007. [accessed 13 April 2013].

Jadhav SH, Sarkar SN, Tripathit HC. Cytogenetic effects of a mixture of selected metals following subchronic exposure through drinking water in male rats. Indian J Exp Biol 2006;44:997-1005.

Kiyohara C, Yoshimasu K. Genetic polymorphisms in the nucleotide excision repair pathway and lung cancer risk: a meta-analysis. Int J Med Sci 2007;4:59-71.

Lin D-X, Tang Y-M, Peng Q, Lu S-X, Ambrosone CB, Kadlubar FF. Susceptibility to esophageal cancer and genetic polymorphisms in glutathione s transferases T1, P1, and M1 and cytochrome P450 2E1. Cancer Epidemiol Biomarkers Prev 1998;7:1013-8.

Liu Q, Cao J, Liu Y, Lü YM, Qin B, Jiang B, et al. Follow-up study by chromosome aberration analysis and micronucleus assays in victims accidentally exposed to 60Co radiation. Health Phys 2010;98:885-8.

Mateuca RA, Roelants M, Iarmarcovai G, Aka PV, Godderis L, Tremp A, et al. hOGG1326, XRCC1399 and XRCC3241 polymorphisms influence micronucleus frequencies in human lymphocytes in vivo. Mutagenesis 2008;23:35-41.

McWilliams RR, Bamlet WR, Cunningham JM, Goode EL, Andrade M, Boardman LA, et al. Polymorphisms in DNA repair genes, smoking, and pancreatic adenocarcinoma risk. Cancer Res 2008;68:4928-35.

Møller P. Assessment of reference values for DNA damage detected by the comet assay in human blood cell DNA. Mutat Res 2006;612:84-104.

Mudgal V, Madaan N, Mudgal A, Singh R, Mishra S. Effect of toxic metals on human health. Open Nutraceuticals J. 2010;3:94-9.

Murray R, Bender D, Botham K, Kennelly P, Rodwell V, Weil P, et al. Micronutrients: Vitamins \& Minerals. Harper's Illustrated Biochemistry. 28th ed. New York: McGraw-Hill; 2009. p. 476-8.

Park JY, Park SH, Choi JE, Lee SY, Jeon H-S, Cha S-I, et al. Polymorphisms of the DNA repair gene xeroderma pigmentosum Group A and risk of primary lung cancer. Cancer Epidemiol Biomarkers Prev 2002;11:993-7.

Pavanello S, Clonfero E. Biological indicators of genotoxic risk and metabolic polymorphisms. Mutat Res 2000;463:285-308.

Roma-Torres J, Teixeira JP, Silva S, Laffon B, Cunha LM, Méndez J, et al. Evaluation of genotoxicity in a group of workers from a petroleum refinery aromatics plant Mutat Res 2006;604:19-27.

Rossi AM, Hansteen I-L, Skjelbred CF, Ballardin M, Maggini V, Murgia E, et al. Association between frequency of chromosomal aberrations and cancer risk is not influenced by genetic polymorphisms in GSTM1 and GSTT1. Environ Health Perspect 2009;117:203-8.

Salgueiro A, Avila P, Pereira H, Silva E. Assessment of the Impact of Pollution by Arsenic in the Vicinity of Panasqueira Mine (Portugal). In: Atkinson PM, Lloyd $\mathrm{CD}$, editors. geoENV VII - Geostatistics for Environmental Applications: Proceedings of the Seventh European Conference on Geostatistics for Environmental Applications, 8-10 September 2008, Southampton, UK. Dordrecht, London: Springer-Verlag; 2008. p. 151-60.
Shen M, Berndt SI, Rothman N, Mumford JL, He X, Yeager M, et al. Polymorphisms in the DNA base excision repair genes APEX1 and XRCC1 and lung cancer risk in Xuan Wei, China. Anticancer Res 2005;25:537-42.

Silva SN, Azevedo AP, Teixeira V, Pina JE, Rueff J, Gaspar JF. The role of GSTA2 polymorphisms and haplotypes in breast cancer susceptibility: a case-control study in the Portuguese population. Oncol Rep 2009;22:593-8.

Silva SN, Tomar M, Paulo C, Gomes BC, Azevedo AP, Teixeira V, et al. Breast cancer risk and common single nucleotide polymorphisms in homologous recombination DNA repair pathway genes XRCC2, XRCC3, NBS1 and RAD51. Cancer Epidemiol 2010;34:85-92.

Skjelbred CF, Svendsen M, Haugan V, Eek AK, Clausen KO, Kure EH, et al. Influence of GSTM1, GSTT1, GSTP1, NAT1, NAT2, EPHX1, MTR and MTHFR polymorphism on chromosomal aberration frequencies in human lymphocytes. Carcinogenesis 2011;32:399-405.

Smith TR, Levine EA, Perrier ND, Miller MS, Freimanis RI, Lohman K, et al. DNA-repai genetic polymorphisms and breast cancer risk. Cancer Epidemiol Biomarkers Prev 2003;12:1200-4.

Surrallés J, Falck G, Norppa $\mathrm{H}$. In vivo cytogenetic damage revealed by FISH analysis of micronuclei in uncultured human T lymphocytes. Cytogenet Cell Genet 1996;75: 151-4.

Taooka Y, Takeichi N, Noso Y, Kawano N, Apsalikov K, Hoshi M. Increased T-cell receptor mutation frequency in radiation-exposed residents living near the Semipalatinsk nuclear test site. J Radiat Res 2006;47:179-81.

Teixeira JP, Gaspar J, Martinho G, Silva S, Rodrigues S, Mayan O, et al. Aromatic DNA adduct levels in coke oven workers: correlation with polymorphisms in genes GSTP1, GSTM1, GSTT1 and CYP1A1. Mutat Res 2002;517:147-55.

Teixeira JP, Gaspar J, Silva S, Torres J, Silva S, Azevedo MC, et al. Occupational exposure to styrene: modulation of cytogenetic damage and levels of urinary metabolites of styrene by polymorphisms in genes CYP2E1, EPHX1, GSTM1, GSTT1 and GSTP1. Toxicology 2004;195:231-42.

Therman E. Human Chromosomes: Structure, Behavior, Effects. New York: Springer-Verlag; 1980.

van Vuuren AJ, Appeldoorn E, Odijk H, Humbert S, Moncollin V, Eker AP, et al Partial characterization of the DNA repair protein complex, containing the ERCC1, ERCC4, ERCC11 and XPF correcting activities. Mutat Res 1995;337: 25-39.

Yamane A, Kohno T, Ito K, Sunaga N, Aoki K, Yoshimura K, et al. Differential ability of polymorphic OGG1 proteins to suppress mutagenesis induced by 8-hydroxyguanine in human cell in vivo. Carcinogenesis 2004;25:1689-94.

Yu H, Zhao H, Wang LE, Liu Z, Li D, Wei Q. Correlation between base-excision repair gene polymorphisms and levels of in-vitro BPDE-induced DNA adducts in cultured peripheral blood lymphocytes. PLoS One 2012;7:e40131.

Zienolddiny S, Campa D, Lind H, Ryberg D, Skaug V, Stangeland L, et al. Polymorphisms of DNA repair genes and risk of non-small cell lung cancer. Carcinogenesis 2006;27: 560-7. 